\title{
Effect of postnatal malnutrition on hyperoxia-induced newborn lung development
}

\author{
M.M.G.B. Mataloun ${ }^{1}$, C.R. Leone ${ }^{1}$, R.S. Mascaretti², M. Dohlnikoff ${ }^{3}$ and C.M. Rebello² \\ ${ }^{1}$ Pediatria Neonatal, ${ }^{2}$ Laboratório de Pesquisa Experimental, Departamento de Pediatria, Instituto da \\ Criança "Prof. Pedro de Alcântara", Universidade de São Paulo, São Paulo, SP, Brasil \\ ${ }^{3}$ Departamento de Patologia, Faculdade de Medicina, Universidade de São Paulo, São Paulo, SP, Brasil \\ Correspondence to: M.M.G.B. Mataloun, Rua Albuquerque Lins, 902-93, 01230-000 São Paulo, SP, Brasil \\ Fax: +55-11-3821-5865. E-mail: mataloun@uol.com.br
}

\begin{abstract}
Several factors are associated with bronchopulmonary dysplasia. Among them, hyperoxia and lung immaturity are considered to be fundamental; however, the effect of malnutrition is unknown. Our objective was to evaluate the effects of 7 days of postnatal malnutrition and hyperoxia on lung weight, volume, water content, and pulmonary morphometry of premature rabbits. After csection, 28-day-old New Zealand white rabbits were randomized into four groups: control diet and room air (CA, $N=17)$, control diet and $\geq 95 \% \mathrm{O}_{2}(\mathrm{CH}, \mathrm{N}=17)$, malnutrition and room air ( $\left.\mathrm{MA}, \mathrm{N}=18\right)$, and malnutrition and $\geq 95 \% \mathrm{O}_{2}(\mathrm{MH}, \mathrm{N}=18)$. Malnutrition was defined as a $30 \%$ reduction of all the nutrients provided in the control diet. Treatments were maintained for 7 days, after which histological and morphometric analyses were conducted. Lung slices were stained with hematoxylin-eosin, modified orcein-resorcin or picrosirius. The results of morphometric analysis indicated that postnatal malnutrition decreased lung weight (CA: $0.83 \pm 0.19 ; \mathrm{CH}: 0.96 \pm 0.28$; MA: $0.65 \pm 0.17$; $\mathrm{MH}: 0.79 \pm 0.22 \mathrm{~g}$ ) and water content, as well as the number of alveoli (CA: $12.43 \pm 3.07$; $\mathrm{CH}: 8.85 \pm 1.46$; MA: $7.33 \pm 0.88$; $\mathrm{MH}: 6.36 \pm 1.53 \times 10^{-3} / \mathrm{mm}$ ) and elastic and collagen fibers. Hyperoxia reduced the number of alveoli and increased septal thickening and the mean linear intercept. The reduction of alveolar number, collagen and elastic fibers was intensified when malnutrition and hyperoxia were associated. These data suggest that dietary restriction enhances the magnitude of hyperoxia-induced alveolar growth arrest and lung parenchymal remodeling. It is interesting to consider the important influence of postnatal nutrition upon lung development and bronchopulmonary dysplasia.
\end{abstract}

Key words: Postnatal malnutrition; Hyperoxia; Lung development; Rabbit

Research supported by FAPESP.

Received September 4, 2008. Accepted April 13, 2009

\section{Introduction}

Bronchopulmonary dysplasia involves histopathological pulmonary changes resulting from an inflammatory process induced by hyperoxia $(1,2)$, infection (3), and mechanical ventilation (4), conditions associated with the peculiarities of the developing immature lung.

Several experimental studies have described the acute lung injury caused by hyperoxia in adult animals $(5,6)$ as well as in premature animals (7-14) during the period in which the lung is still in the process of alveolarization. This injury is characterized by arrested alveolar and pulmonary microvascular development $(5,6,15,16)$.
Regarding the influence of nutrition on lung development, it has been shown that tissue elasticity was decreased in the lungs of starved adult rats $(17,18)$ and that this effect was not reversed after resumption of feeding, probably due to irreversible damage to airspaces caused by the loss of connective tissue (17). Several investigators have described a reduction of somatic growth, lung volume and weight (19-21) in term newborn rats subjected to nutritional restriction during the neonatal period. It was also demonstrated that the total number of alveoli and the internal surface area of the lung were significantly reduced in starved newborn rats (19). However, other investigators did not observe any influence of malnutrition on the pulmo- 
nary architecture $(20,21)$. It is noteworthy that, although the effects of hyperoxia and malnutrition on lung development have been individually demonstrated, the consequences of the combined treatment on lung growth and development have not been described.

Therefore, we hypothesized that malnutrition will decrease alveolarization as well as interrupt and disorganize the deposition of elastic fibers and collagen in preterm rabbits exposed to hyperoxia. The objective of this study was to evaluate the effects of postnatal malnutrition alone or in combination with 7 days of hyperoxia on lung morphometry in premature rabbits.

\section{Material and Methods}

Protocols were approved by the Ethics Committee for the Analysis of Research Projects, University Hospital, School of Medicine, University of São Paulo. The study was carried out in the Experimental Research Laboratory of the Department of Pediatrics.

\section{Animal preparation}

Timed-pregnant New Zealand white rabbits (Benjamin Fleder $^{\circledR}$, Moji das Cruzes, SP, Brazil) at the 28th day of gestation were used. The pregnant rabbits received intramuscular ketamine $(10 \mathrm{mg} / \mathrm{kg})$ and acepromazine $(0.1 \mathrm{mg} /$ $\mathrm{kg}$ ), and rachianesthesia with $2 \%$ marcaine-xylocaine solution $(1: 1, v / v, 2 \mathrm{~mL})$. After c-section, the pups were identified by a number marked on the dorsal region and weighed over a thermal mattress and under radiant heat. The pups were exposed to $30 \% \mathrm{O}_{2}$ during the first $30 \mathrm{~min}$ of life and the dams were euthanized with an injection of 5 $\mathrm{mL}$ pentobarbital.

After the initial period of adaptation, the surviving newborns were randomly divided into one of four groups: CA: control diet and room air $(\mathrm{N}=17), \mathrm{CH}$ : control diet and hyperoxia $\left(\geq 95 \% \mathrm{O}_{2}\right)(\mathrm{N}=17)$, $\mathrm{MA}$ : malnutrition and room air $(\mathrm{N}=18)$, or $\mathrm{MH}$ : malnutrition and hyperoxia $(\mathrm{N}=18)$. The offspring were sacrificed on day 7 .

The animals were kept in incubators (Fanem ${ }^{\circledR}$, Brazil) at $30-32^{\circ} \mathrm{C}$. To prevent infection, the incubators were disinfected, distilled water was used in the nebulizers, the diet was sterilized, and the sawdust was autoclaved. From the 3rd day of life, the animals received crystalline penicillin $\left(20,000\right.$ units $\cdot \mathrm{kg}^{-1} \cdot$ day $\left.^{-1}\right)$ and streptomycin $\left(20 \mathrm{mg} \cdot \mathrm{kg}^{-1} \cdot\right.$ day $\left.^{-1}\right)$ by the intramuscular route once a day as prophylaxis against infection, which was the most frequent cause of death in the pilot studies. Pups also received a single intramuscular dose of vitamin $\mathrm{K}(0.002 \mathrm{mg} / \mathrm{kg})$ on day 3 in order to prevent pulmonary hemorrhage.

A lacteal formula with a composition similar to that of rabbit milk $(22,23)$ and to that described in the literature $(8,13,24)$ was developed because the pups were unable to suck. The control diet consisted of a mixture of $5 \mathrm{~g} \mathrm{AL} 110$ Formula (Nestlé ${ }^{\circledR}$, Brazil), 5 g casein (Support ${ }^{\circledR}$, Brazil), 15 $\mathrm{mL}$ triglyceride CMAGE (Support ${ }^{\circledR}$ ), 1 drop Vitanove ${ }^{\circledR}$ (USP, Brazil), and distilled water (100 mL qsp), which supplied $5.3 \mathrm{~g}$ protein, $16.2 \mathrm{~g}$ fat, $2.8 \mathrm{~g}$ dextrin-maltase, and $155 \mathrm{kcal}$ per $100 \mathrm{~mL}$. Malnutrition was defined as a $30 \%$ reduction of all nutrients of the control diet, based on experimental models of malnutrition and hyperoxia in rats $(21,24)$. The ponderal evolution of pups in this study was similar to a study that used the same formula (8). All animals were fed twice a day through an orogastric feeding tube (4 Fr) adapted to a graduated syringe, because the premature rabbits were unable to suck. The feeding volumes were increased over time from $50 \mathrm{~mL} / \mathrm{kg}$ on day 0 to $100 \mathrm{~mL} / \mathrm{kg}$ on day 1 , to $150 \mathrm{~mL} / \mathrm{kg}$ on day 2 and to $200 \mathrm{~mL} \cdot \mathrm{kg}^{-1} \cdot \mathrm{day}^{-1}$ on days 3-10. The same volume was given to all groups.

The animals were weighed daily in the morning on a precise analytical balance (TR 403, Denver Instrument Company ${ }^{\circledR}$, USA). All measurements were repeated three times and averaged.

\section{Exposure to hyperoxia}

Heated and humidified oxygen was administered through a sealed acrylic chamber with neonatal nebulizers (Intermed ${ }^{\circledR}$, Brazil) with a continuous flow of $3 \mathrm{~L} / \mathrm{min}$. This continuous flow prevented $\mathrm{CO}_{2}$ accumulation and achieved a constant level of $95 \% \mathrm{O}_{2}$. The oxygen concentration was continuously monitored with an environment oximeter (Dixtal ${ }^{\circledR}$, Brazil).

\section{Histology}

The animals were euthanized with an intraperitoneal injection of pentobarbital sodium $(25 \mathrm{mg} / \mathrm{kg})$ and by sectioning of the abdominal aorta. The trachea was cannulated with a Silastic cannula measuring $1 \mathrm{~mm}$ in diameter, after which bilateral pneumothoraces were produced by puncture of the diaphragm from the abdominal surface. The tracheal cannula was connected to a water column, and the lungs were inflated with air at a pressure of $30 \mathrm{cmH}_{2} \mathrm{O}$, followed by tracheal ligature. The lungs were removed from the thorax and submerged into a $10 \%$ buffered formol solution for $24 \mathrm{~h}$. The lungs were weighed three times, and the arithmetic mean was calculated. Lung volume was measured three times by the water displacement method (25) and the mean value was obtained. These measurements were repeated if two values differed by more than $0.05 \mathrm{~mL}$. A correction factor was not used for humid and dehydrated (wet and dry) values because all lungs were processed identically. The lung weight/body weight ratio was determined at the time of 
euthanasia, and the specific lung volume was determined by dividing the lung volume by $100 \mathrm{~g}$ body weight $(\mathrm{mL} / 100$ g body weight) (26).

The lung water content was quantified as the difference between the wet and dried lung weights. The left lung was used for this measurement and was weighed both in the humid state and after exposure to $80^{\circ} \mathrm{C}$ for $72 \mathrm{~h}$ or until a constant lung weight was obtained (27).

Sagittal 1-mm tissue slices were removed from the distal portion of the inferior right lobe and preserved in $70 \%$ ethyl alcohol until paraffin embedding and serial sectioning to a thickness of $5 \mu \mathrm{m}$. The sections were stained with hematoxylin-eosin (HE), with modified resorcin-orcein for elastic fiber visualization, and with picrosirius for collagen visualization.

\section{Morphometric analysis}

Morphometric analysis was performed by the same investigator in a blind manner, using a light microscope (Nikon E-600, Japan) with a grid (100 points/50 lines) in the eyepiece and an image analysis software (Image-Pro ${ }^{\circledR}$, Media Cybernetics Inc. ${ }^{\mathrm{TM}}$, USA).

Each HE-stained slide was captured at 100X magnification with the image analysis software. Serial images from slides, but not overlying parenchymal regions, with three straight lines traced at distinct levels from pleura to pleura were captured, and the intercepted alveolar walls were counted. The sum of the intercepted alveolar walls was divided by two to obtain the number of alveoli intercepted. The length of each straight line was measured with the image analysis software. The mean number of alveoli per slide was calculated by dividing the number of alveoli obtained by the sum of the length of the three lines. This gives the number of alveoli per unit length (alveolar number $\left.x 10^{-3} / \mu \mathrm{m}\right)(28)$.

The mean linear intercept $(\mathrm{Lm})$ was calculated in ten 100X fields per slide (29). Fifty alveolar septa were measured with the image analyzer (400X) and graded according to the distance between epithelial basement membranes (30). The proportions of collagen and elastic fibers in the pulmonary parenchyma were determined as the relation between the number of points falling on stained and unstained tissue. Measurements were performed in twenty 400X fields per animal using a 100-point/50-line grid (31). The parenchyma points were estimated by counting points through the grid, considering all points that spanned the tissues as parenchyma points, except blood vessels and bronchi measuring $>2 \mathrm{~mm}$ in diameter.

\section{Statistical analysis}

Analysis of variance for repeated measures was used for group comparisons of the changes in body weight during the study period (32). The assumption of a variable normal distribution was confirmed by the construction of descriptive graphics, and multiple comparisons were made based on Wald Statistics (33). One-way analysis of variance (ANOVA) was used to compare lung weights, numbers of lung weight/specific lung volume alveoli, alveolar septum thickness, Lm values, and collagen and elastic fiber proportions. The sample size calculation was based on the assumption that there would be a difference of $10 \%$ between the groups in mean number of alveoli, an $\alpha$ value of $5 \%$ and a power of $80 \%$. On the basis of our pilot study, the $n$ calculated for each group was 17 . A P value $<0.05$ was considered to be statistically significant.

\section{Results}

There were 17 rabbits in the CA group, 17 in the $\mathrm{CH}$ group, 18 in the MA group, and 18 in the $\mathrm{MH}$ group. Analysis of variance for repeated measures did not reveal any differences in weight between groups from birth to sacrifice. However, the average birth weight of the CA group was lower than that of the MA group. The differences between mean birth weight and weight at the time of sacrifice were calculated, showing a higher weight gain for the $\mathrm{CH}$ group than for the $\mathrm{MH}$ group $(\mathrm{P}=0.0001$, with no differences between the CA and MA groups (Figure 1).

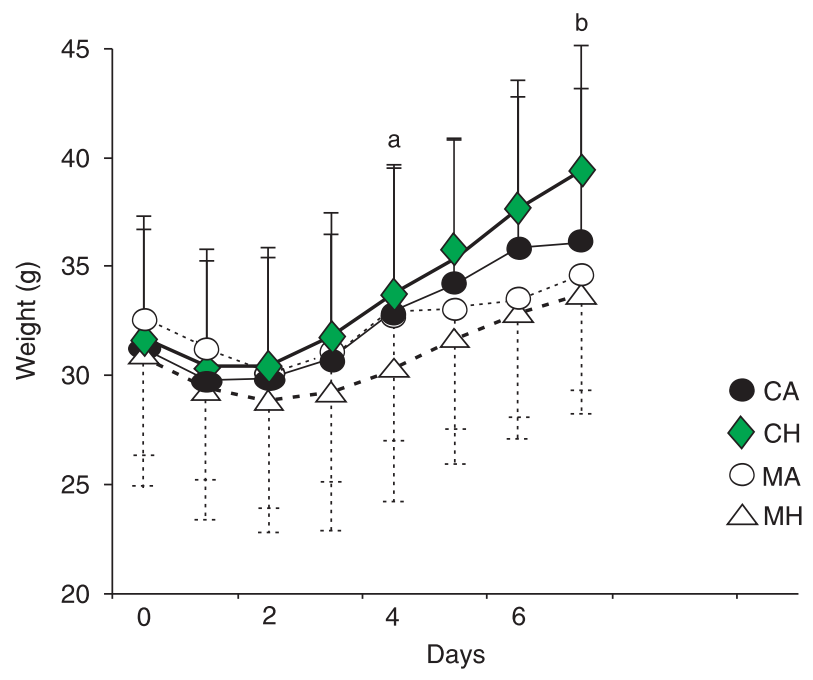

Figure 1. Daily weight curves for the study groups. Data are reported as means $\pm \mathrm{SD}$. $\mathrm{CA}=$ control diet and room air; $\mathrm{CH}=$ control diet and hyperoxia; $\mathrm{MA}=$ malnutrition and room air; $\mathrm{MH}=$ malnutrition and hyperoxia. ${ }^{\mathrm{a}} \mathrm{CH}$ vs $\mathrm{MH}$; ${ }^{\mathrm{b}} \mathrm{CA}$ vs $\mathrm{MA} . \mathrm{P}=0.05$ (two-way ANOVA). 


\section{Pulmonary effects}

Malnutrition induced lower of lung weight, lung weight corrected for birth weight, specific lung volume and water content $(P<0.05)$ in premature rabbits. This treatment also led to a reduction in alveoli number $(P<0.05)$ and elastic fibers $(P<0.05)$ and in collagen deposition $(P<0.05)$ at 7 days. Hyperoxia resulted in a reduced number of alveoli $(P$ $<0.05)$, greater septal thickness $(P<0.05)$ and an increased $\operatorname{Lm}(P<0.05)$ at 7 days. When the animals were exposed to both malnutrition and hyperoxia, more pronounced reductions in alveolar number $(P<0.05)$ and collagen deposition $(P<0.05)$ were detected.

A thickening of the elastic fibers with a rough aspect was observed in malnutrition and/or hyperoxia in contrast with thin and delicate fibers in control diet and room air.

These results are summarized in Table 1 and Figures 2,3 , and 4 .

Table 1. Effect of postnatal malnutrition and hypoxia on rabbits at 7 days of life.

\begin{tabular}{lccrr}
\hline & $\mathrm{CA}(\mathrm{N}=17)$ & $\mathrm{CH}(\mathrm{N}=17)$ & $\mathrm{MA}(\mathrm{N}=18)$ & $\mathrm{MH}(\mathrm{N}=18)$ \\
\hline Lung weight $(\mathrm{g})$ & $0.83 \pm 0.19$ & $0.96 \pm 0.28$ & $0.65 \pm 0.17^{\mathrm{a}}$ & $0.79 \pm 0.22^{\mathrm{bd}}$ \\
Lung weight/body weight & $0.027 \pm 0.006$ & $0.027 \pm 0.008$ & $0.019 \pm 0.004^{\mathrm{a}}$ & $0.023 \pm 0.005^{\mathrm{d}}$ \\
Specific lung volume $(\mathrm{mL} / 100 \mathrm{~g})$ & $7.77 \pm 3.57$ & $7.30 \pm 5.80$ & $4.78 \pm 1.61^{\mathrm{a}}$ & $3.67 \pm 1.43^{\mathrm{bd}}$ \\
Lung water content & $91.77 \pm 1.94$ & $90.30 \pm 2.48$ & $80.37 \pm 4.13^{\mathrm{a}}$ & $77.54 \pm 4.60^{\mathrm{b}}$ \\
Mean linear intercept $(\mu \mathrm{g})$ & $59.10 \pm 9.12$ & $73.70 \pm 13.40^{\mathrm{c}}$ & $60.33 \pm 10.46$ & $75.83 \pm 14.50$ \\
Alveolar septum $(\mu \mathrm{m})$ & $9.62 \pm 2.48$ & $12.59 \pm 4.68^{\mathrm{c}}$ & $5.23 \pm 3.41^{\mathrm{a}}$ & $12.48 \pm 7.01^{\mathrm{d}}$ \\
\hline
\end{tabular}

$\mathrm{CA}=$ control diet and room air; $\mathrm{CH}=$ control diet and hyperoxia; $\mathrm{MA}=$ malnutrition and room air; $\mathrm{MH}=$ malnutrition and hyperoxia. $\mathrm{P}<0.05$ : ${ }^{\mathrm{a}} \mathrm{CA}$ vs $\mathrm{MA}$; ${ }^{\mathrm{b}} \mathrm{CH}$ vs $\mathrm{MH} ;{ }^{\mathrm{c}} \mathrm{CA}$ vs $\mathrm{CH}$; ${ }^{\mathrm{MA}}$ vs $\mathrm{MH}$ (one-way ANOVA).

Figure 2. $A$, Alveolar number $\left(\times 10^{-3} / \mathrm{mm}\right)$ in the control and malnutrition groups at 7 days of life. Data are reported as means $\pm \mathrm{SD}$. CA = control diet and room air; $\mathrm{CH}=$ control diet and hyperoxia; $\mathrm{MA}=$ malnutrition and room air; $\mathrm{MH}=$ malnutrition and hyperoxia. Alveolar number decreased in the groups submitted to malnutrition or hyperoxia, and a more intense reduction was observed when both challenges were combined. ${ }^{*} \mathrm{P}<0.05$ (one-way ANOVA). B, Lung sections showing the alveoli. Hematoxylin-eosin staining. Magnification: 100X. Hyperoxia and malnutrition reduced alveolar number. When the animals were exposed to both malnutrition and hyperoxia, more pronounced reductions in alveolar number $(P<0.05)$ were observed. Alveoli are shown by arrows. Inflammatory process is observed in the hyperoxia groups. One-way ANOVA. Magnification bar $=100 \mu \mathrm{m}$ for all panels.

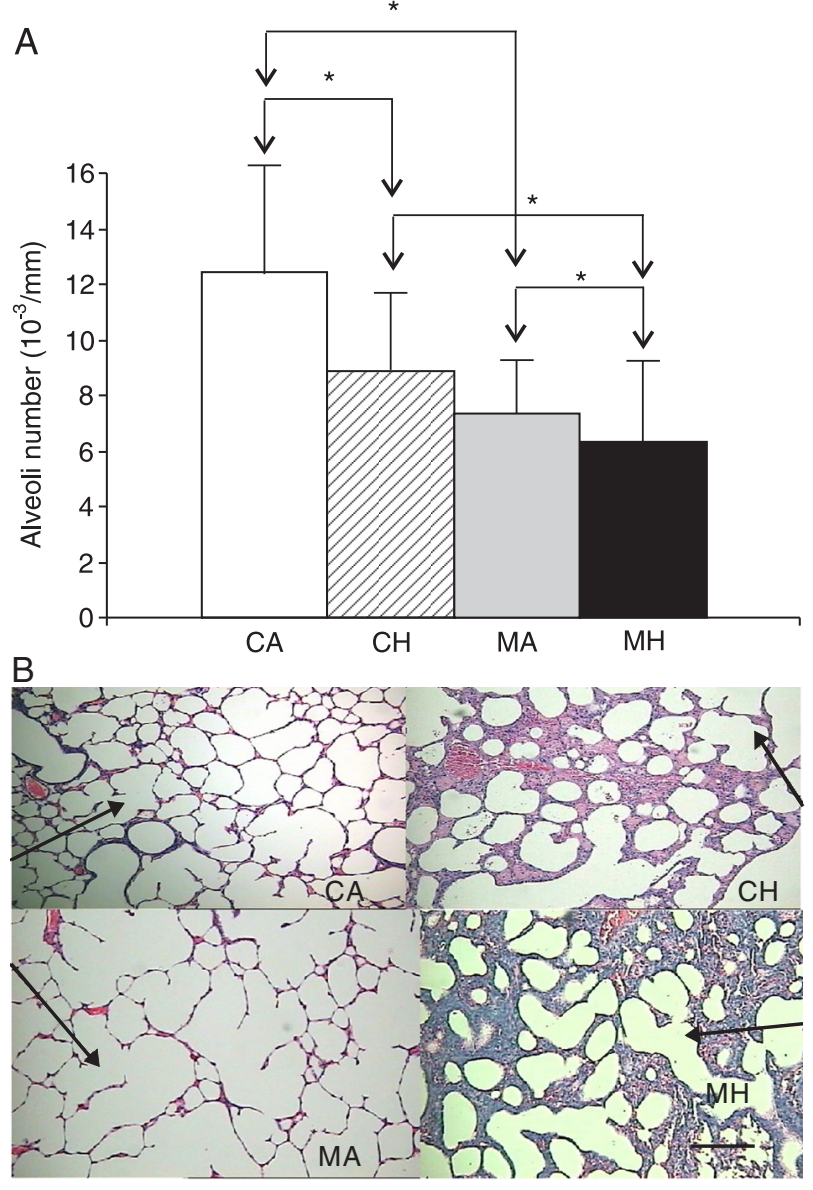


A

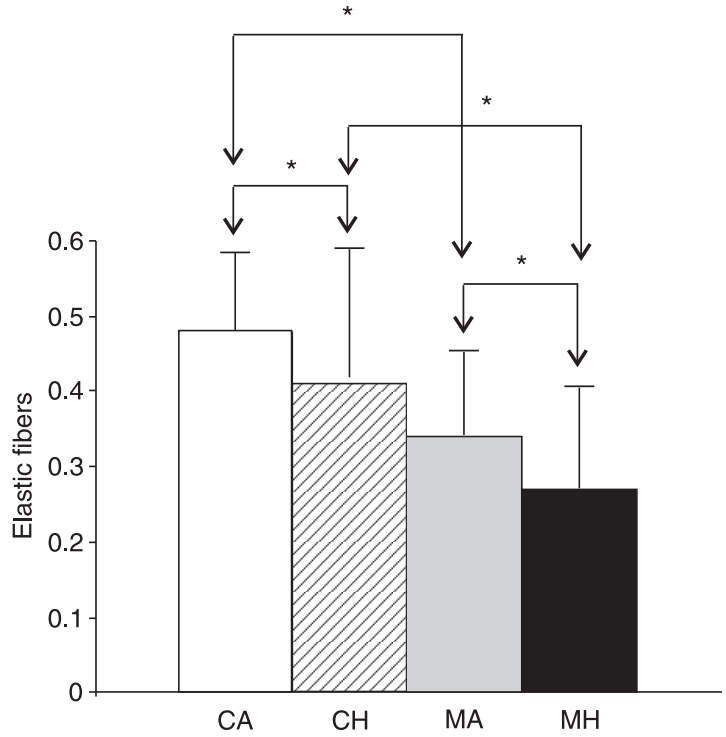

B

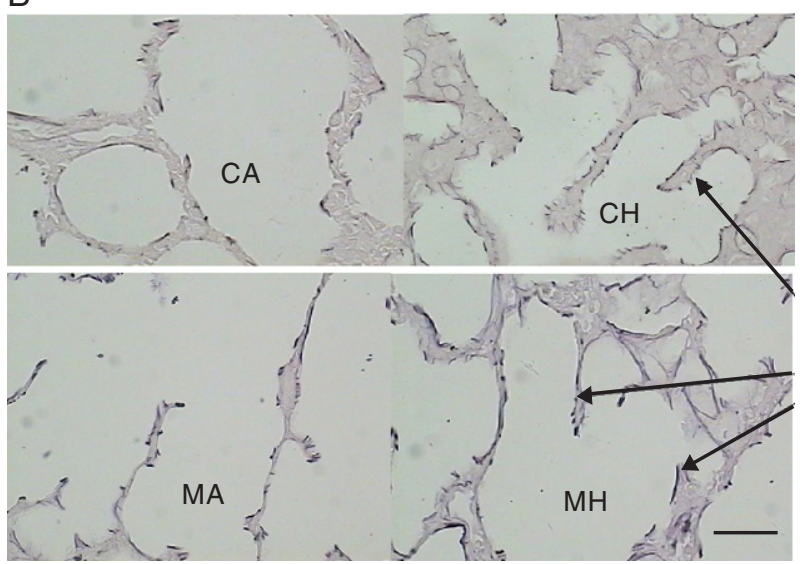

Figure 3. $A$, Elastic fibers in the control and malnutrition groups at 7 days of normoxia or hypoxia exposure. $\mathrm{CA}=$ control diet and room air; $\mathrm{CH}=$ control diet and hyperoxia; $\mathrm{MA}=$ malnutrition and room air; $\mathrm{MH}=$ malnutrition and hyperoxia. $B$, Lung slides of premature rabbits at 7 days of life - modified resorcin-orcein staining (magnification: 400X) - a thickening of the elastic fibers with a rough aspect was observed in the malnutrition and/or hyperoxia groups in contrast with thin and delicate fibers in the control diet and room air groups. Elastic fibers - stained in black (arrows). ${ }^{*} \mathrm{P}<0.05$ (one-way ANOVA). Magnification bar $=100$ $\mu \mathrm{m}$ for both panels.

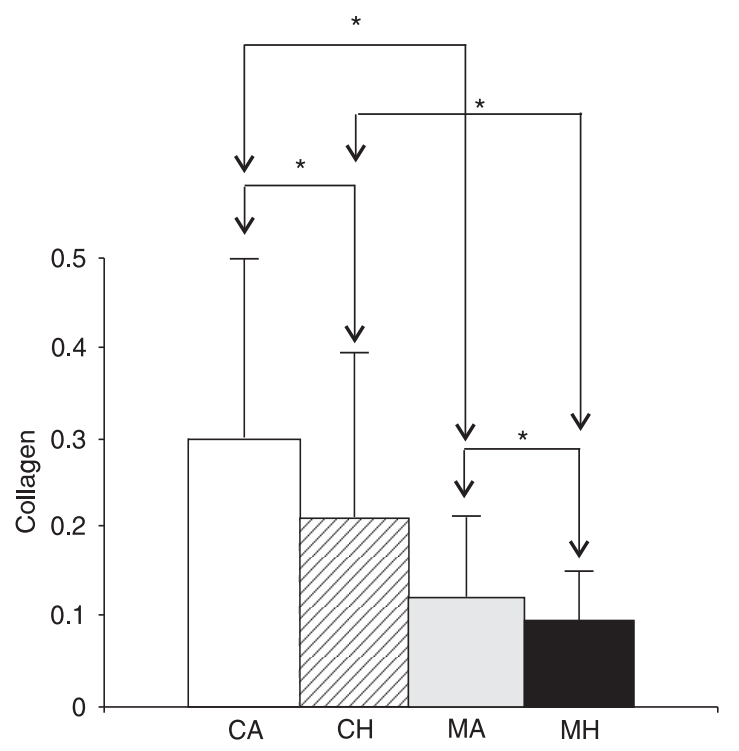

Figure 4. Collagen proportion in the control and malnutrition groups at 7 days of normoxia or hypoxia exposure. Data are reported as means \pm SD. The collagen proportion decreased in the groups submitted to malnutrition or hyperoxia, and a more intense reduction occurred when both challenges were combined. $\mathrm{CA}=$ control diet and room air; $\mathrm{CH}=$ control diet and hyperoxia; $\mathrm{MA}=$ malnutrition and room air; $\mathrm{MH}=$ malnutrition and hyperoxia. The proportions of collagen and elastic fibers in the pulmonary parenchyma were determined as the relation between the number of points falling on stained and unstained tissue. Measurements were performed in twenty 400X fields per animal using a 100 -point $/ 50$-line grid. ${ }^{*} \mathrm{P}<0.05$ (one-way ANOVA). 


\section{Discussion}

The present study showed that malnutrition reduced lung weight, lung weight/birth weight ratio, specific lung volume and water content, as well as the number of alveoli and elastic fibers and collagen deposition. Hyperoxia reduced alveolar number and led to increased values of septal thickness and mean linear intercept. Combined malnutrition and hyperoxia caused a more drastic reduction in alveolar number and collagen deposition.

This premature rabbit model is particularly suitable for analysis of factors that influence alveolarization. In rabbits, a gestational age of 28 days is the lower limit of viability (8), as well as the point at which lung development is at the end of the saccular phase and at the beginning of the alveolar phase $(10,11)$. Preterm rabbits at 27 days of gestation are a validated animal model for surfactant deficiency and are widely used for surfactant replacement studies (34). The preterm rabbit at 28 days of gestation has an increased surfactant pool and is not appropriate for studies of surfactant deficiency, but it permits the evaluation of the effects of hyperoxia and malnutrition on immature lungs in the early stages of alveolarization. In addition, this rabbit model is less costly and more easily reproduced, thus permitting easier execution of procedures as well as greater precision with respect to gestational age, as ovulation may be induced.

A weight reduction of more than $20 \%$ in pups exposed to malnutrition was observed in the pilot study, leading us to choose this level of malnutrition. The most common experimental model of nutritional restriction in the literature is the one that manipulates the number of pups fed by the same mother, i.e., increasing or reducing the number of pups per female $(19,20)$. The other models use a reduction of several degrees of nutrients administered to animals. As the pups of the present study were unable to suck, a $30 \%$ reduction of the nutrients of the control diet was chosen, as also done in other studies $(19,20,35,36)$. This diet is similar to that used in other premature rabbit models $(8,13)$. Based on previous studies with preterm rabbits $(8,13)$, we decided to use a diet volume corresponding to $20 \%$ of body weight between the $3 \mathrm{rd}$ and 7 th days of life based on earlier studies with preterm rabbits $(8,13)$.

The use of $95 \%$ oxygen concentration in order to obtain an intense inflammatory response over a short period of time was chosen based on data from previous studies $(5,37)$.

Malnutrition during the immediate postnatal period yielded lower lung weights as also observed in previous studies $(19,20)$, in addition to reduced lung water content and specific lung volume after 7 days of treatment. Although some studies using models of malnutrition found that this treatment induced higher specific lung volumes, other studies obtained contradictory results $(14,15)$. The studies that detected higher specific lung volumes also found greater alveolar size, while a subset also observed emphysematous segments (36). These inconsistent results might reflect differences in the degree of malnutrition or the type of nutrients restricted, as well as the time of onset of treatment.

The reduction in alveolar number attributed to malnutrition was significant, similar to other studies that examined this period of rapid alveolar production in several species, including rabbits (12). This effect occurred without changing the dimensions of the alveoli, as observed in a previous study (14), suggesting the existence of a mechanism other than septation by which malnutrition could alter alveolar formation. It is known that elastic fiber deposition in the alveolar wall is a major mechanism involved in alveolarization that results in further crist formation (38). Our results suggest that the reduction of elastic fibers and collagen deposition due to malnutrition impairs the alveolarization process. This effect of malnutrition has been interpreted to be a consequence of substratum depletion $(19,39)$. Therefore, a reduction in these deposits could interfere with alveolar septation, causing arrested alveolar development.

Significant histopathological pulmonary changes were observed due to malnutrition, despite the fact that there were no differences in body weight gain between the control diet and malnutrition groups. Probably, the duration of malnutrition in this study was not long enough to produce changes in weight gain. However, in an earlier study using this experimental model for a period of 11 days, the authors described a reduction of body weight growth in the malnutrition group (39). These results suggest that body weight may be a poor nutritional marker of short duration malnutrition. The mechanism by which hyperoxia induces alveolar arrest has been shown to be mediated by elastic and collagen fiber disorganization, and secondarily by oxidative stress and the inflammatory process (15). In the present study, hyperoxia decreased alveolar number and increased alveolar septal thickening and Lm, suggesting arrested alveolarization. These results are consistent with earlier studies of lung injury due to hyperoxia $(2,3,5,7)$. Septal thickening could indicate the presence of a fibro-proliferative process $(5,7)$, which may be responsible for the increase of the mean Lm intercept in these samples. However, this Lm increase may also have been due to the inhibition of septation and to alteration in the development of the alveolar capillaries $(2,5,6,15,16)$. Hyperoxia did not increase lung water content in the pres- 
ent study, as was expected (27). This may have been due to the shorter time of exposure to hyperoxia in our study. Incidentally, collagen and elastic fiber deposition did not differ between the hyperoxia and room air groups.

Combined malnutrition and hyperoxia treatment induced an enhanced reduction of alveolar number as well as elastic fiber and collagen deposition.

Malnutrition affects lysyl-oxidase production due to the global deficiency of nutrients (40). This enzyme is involved in the initial step of crista formation and consequently elastin deposition. In this manner, nutrition can play an important role in elastin production and deposition and thus enhance the effects of hyperoxia.

\section{References}

1. Bonikos DS, Bensch KG, Northway WH Jr, Edwards DK. Bronchopulmonary dysplasia: the pulmonary pathologic sequel of necrotizing bronchiolitis and pulmonary fibrosis. Hum Pathol 1976; 7: 643-666.

2. Warner BB, Stuart LA, Papes RA, Wispé JR. Functional and pathological effects of prolonged hyperoxia in neonatal mice. Am J Physiol 1998; 275: L110- L117.

3. Jobe $A H$, Newnham JP, Willet KE, Sly P, Ervin MG, Bachurski $C$, et al. Effects of antenatal endotoxin and glucocorticoids on the lungs of preterm lambs. Am J Obstet Gynecol 2000; 182: 401-408.

4. Coalson JJ, Winter VT, Siler-Khodr T, Yoder BA. Neonatal chronic lung disease in extremely immature baboons. Am J Respir Crit Care Med 1999; 160: 1333-1346.

5. Crapo JD. Morphologic changes in pulmonary oxygen toxicity. Annu Rev Physiol 1986; 48: 721-731.

6. Dauger S, Ferkdadji L, Saumon G, Vardon G, Peuchmaur M, Gaultier C, et al. Neonatal exposure to $65 \%$ oxygen durably impairs lung architecture and breathing pattern in adult mice. Chest 2003; 123: 530-538.

7. Tanswell AK, Wong L, Possmayer F, Freeman BA. The preterm rat: a model for studies of acute and chronic neonatal lung disease. Pediatr Res 1989; 25: 525-529.

8. Lorenzo AV. The preterm rabbit: a model for the study of acute and chronic effects of premature birth. Pediatr Res 1985; 19: 201-205

9. Johnsson H, Eriksson L, Jonzon A, Laurent TC, Sedin G. Lung hyaluronan and water content in preterm and term rabbit pups exposed to oxygen or air. Pediatr Res 1998; 44: 716-722.

10. Karnak I, Muftuoglu S, Cakar N, Tanyel FC. Organ growth and lung maturation in rabbit fetuses. Res Exp Med 1999; 198: 277-287.

11. Kovar J, Sly PD, Willet KE. Postnatal alveolar development of the rabbit. J Appl Physiol 2002; 93: 629-635.

12. Langley SC, Kelly FJ. Effect of food restriction on hyperoxiainduced lung injury in preterm guinea pig. Am $J$ Physiol 1992; 263: L357-L362.

13. Aprille JR, Rulfs J. A convenient neonatal model for developmental studies requiring artificial diets. Biol Neonate 1976; 30: 109-115.
The relevance of these results is that they suggest that malnutrition might intensify hyperoxia-induced acute lung injury, mainly with respect to decreased alveolarization, in premature rabbits. The clinical significance of this structural change, secondary to the distortion or inhibition of several processes of lung development and growth, corresponds to the "new" bronchopulmonary dysplasia. In this context, nutrition may either facilitate or enhance this process. New recommendations for the nutrition of preterm infants during the neonatal period should be considered in order to contribute to a better short- and long-term clinical outcome.

14. Massaro D, Teich N, Maxwell S, Massaro GD, Whitney P. Postnatal development of alveoli. Regulation and evidence for a critical period in rats. J Clin Invest 1985; 76: $1297-$ 1305.

15. Albertine KH, Jones GP, Starcher BC, Bohnsack JF, Davis $\mathrm{PL}, \mathrm{Cho} \mathrm{SC}$, et al. Chronic lung injury in preterm lambs. Disordered respiratory tract development. Am J Respir Crit Care Med 1999; 159: 945-958

16. Thebaud B. Angiogenesis in lung development, injury and repair: implications for chronic lung disease of prematurity. Neonatology 2007; 91: 291-297.

17. Sahebjami H, Vassalo CL. Effects of starvation and refeeding on lung mechanics and morphometry. Am Rev Respir Dis 1979; 119:443-451.

18. Dias CM, Passaro CP, Cagido VR, Einicker-Lamas M, Lowe $J$, Negri EM, et al. Effects of undernutrition on respiratory mechanics and lung parenchyma remodeling. J Appl Physiol 2004; 97: 1888-1896.

19. Frank L, Groseclose E. Oxygen toxicity in newborn rats: the adverse effects of undernutrition. J Appl Physiol 1982; 53: 1248-1255

20. Das RM. The effects of intermittent starvation on lung development in suckling rats. Am J Pathol 1984; 117: 326332.

21. Kalenga M, Tschanz SA, Burri PH. Protein deficiency and the growing rat lung. II. Morphometric analysis and morphology. Pediatr Res 1995; 37: 789-795.

22. Coates ME, Gregoory ME, Thompson SY. The composition of rabbit's milk. Br J Nutr 1964; 18: 583-586.

23. Sogorb F, Damy SB, Rodrigues UP, Chaguri ICAG. Variação na composição do leite de coelha. Mem Inst Butantan 1991; 53: 175-180.

24. Kerr JS, Riley DJ, Lanza-Jacoby S, Berg RA, Spilker HC, Yu SY, et al. Nutritional emphysema in the rat. Influence of protein depletion and impaired lung growth. Am Rev Respir Dis 1985; 131: 644-650.

25. Scherle W. A simple method for volumetry of organs in quantitative stereology. Mikroskopie 1970; 26: 57-60.

26. Bruce MC, Bruce EN, Janiga K, Chetty A. Hyperoxic exposure of developing rat lung decreases tropoelastin mRNA levels that rebound postexposure. Am J Physiol 1993; 265: 
L293-L300.

27. Chen Y, Martinez MA, Frank L. Prenatal dexamethasone administration to premature rats exposed to prolonged hyperoxia: a new rat model of pulmonary fibrosis (bronchopulmonary dysplasia). J Pediatr 1997; 130: 409-416.

28. Dunnill MS. Quantitative methods in the study of pulmonary pathology. Thorax 1962; 17: 320-328.

29. Thurlbeck WM. The internal surface area of nonemphysematous lungs. Am Rev Respir Dis 1967; 95: 765-773.

30. Stocker JT. Pathologic features of long-standing "healed" bronchopulmonary dysplasia: a study of 283 - to 40-monthold infants. Hum Pathol 1986; 17: 943-961.

31. Dolhnikoff M, Mauad T, Ludwig MS. Extracellular matrix and oscillatory mechanics of rat lung parenchyma in bleomycininduced fibrosis. Am J Respir Crit Care Med 1999; 160: 1750-1757.

32. Timm NH. Multivariate analysis with applications in educations and psychology. Belmont: Wadsworth Publishing Company; 1975.

33. Agresti A. A categorical data analysis. New York: John Wiley and Sons; 1990.

34. Robertson B, Lachmann B. Experimental evaluation of surfactants for replacement therapy. Exp Lung Res 1988; 14:
279-310.

35. Kalenga M, Henquin JC. Protein deprivation from the neonatal period impairs lung development in the rat. Pediatr Res 1987; 22: 45-49.

36. Kalenga M, Tschanz SA, Burri PH. Protein deficiency and the growing rat lung. I. Nutritional findings and related lung volumes. Pediatr Res 1995; 37: 783-788.

37. Crapo JD, Barry BE, Foscue HA, Shelburne J. Structural and biochemical changes in rat lungs occurring during exposures to lethal and adaptive doses of oxygen. Am Rev Respir Dis 1980; 122: 123-143.

38. Bourbon J, Boucherat O, Chailley-Heu B, Delacourt C. Control mechanisms of lung alveolar development and their disorders in bronchopulmonary dysplasia. Pediatr Res 2005; 57: 38R-46R.

39. Mataloun MM, Rebello CM, Mascaretti RS, Dohlnikoff M, Leone CR. Pulmonary responses to nutritional restriction and hyperoxia in premature rabbits. $J$ Pediatr 2006; 82: 179-185.

40. Tinker D, Rucker RB. Role of selected nutrients in synthesis, accumulation, and chemical modification of connective tissue proteins. Physiol Rev 1985; 65: 607-657. 